\title{
Non suicidal self injury and suicidal behavior among adolescents: co-occurrence and associated risk factors
}

\author{
Anju Poudel ${ }^{*}$, Anjana Lamichhane ${ }^{2}$, Kamala Rana Magar ${ }^{3}$ and Gopal Prasad Khanal ${ }^{4}$
}

\begin{abstract}
Background: Non-suicidal self-injury (NSSI) and suicidal behavior (SB) are the major public health problems in adolescents. Despite the increased focus on these phenomena, there exist no reliable data in Nepal. This study aimed to determine the prevalence of NSSI and SB among adolescents. Furthermore the study identified the relationship between these two behaviors and assessed demographic, behavioral, and psychological risk factors of NSSI and SB in Nepalese adolescents in a representative sample of the general population.

Methods: The study was conducted among 730 adolescents studying in grade 9 to 12 of public and private schools of Pokhara Metropolitan city, Nepal. Data were collected through self administered standard tools- Functional Assessment of Self Mutilation (FASM) tool, Suicidal Behaviors Questionnaire-Revised (SBQ-R), Rosenberg self-esteem scale (RSES) and Beck Depression Inventory (BDI). Descriptive statistical measures such as frequency, percentage, mean, standard deviation, range were used to assess demographic characteristics and adolescent's behavior regarding NSSI and suicide. For inferential analysis chi-square and one way ANOVA test was used. Furthermore, to determine the predictors of NSSI and SB, multiple logistic regression analysis was used.

Results: Regarding behavioral characteristics, nearly half of the sample 327 (44.8\%) reported a history of NSSI in past 1 year. Furthermore, $25.8 \%(n=188)$ of the overall sample engaged in minor NSSI only and $3.42 \%(n=25)$ engaged in at least one act of moderate/severe NSSI. The mean number of type of NSSI performed was $2.63 \pm 1.71$. The most common type of NSSI method used were picking at wound (27.3\%), biting self (20.3\%), pulling hair out (11.8\%), cutting self (11.1\%). Boys (52.6\%) were more likely to be engaged in NSSI than girls (47.4\%) $\left(X^{2}=10.298, p=0.002\right)$. Furthermore, among 730 adolescents who completed the SBQ-R questionnaire, 131 (17.9\%) had suicidal behaviors (SB) (as defined by SBQ-R a total score $\geq 7$ ). Regarding sex differences female were significantly higher in life time prevalence of suicidal behavior than male $\left(X^{2}=30.26, p=0.001\right)$. Simple Chi-square tests indicated that NSSI was significantly associated with $\mathrm{SB}\left(X^{2}=58.16, P<.001\right)$. Logistic regressions identified the four significant predictors of NSSI behavior: male, low-level of self-esteem (SE), moderate to severe form of depression and SB. Similarly, significant predictors of SB were: female, low-level of SE, moderate to severe form of depression and NSSI behavior.
\end{abstract}

Conclusion: The prevalence of both NSSI and SB is high in adolescents. Despite the differences between NSSI and SB a significant number of adolescents reported a history of both behaviors. Lower level of SE and moderate to severe

\footnotetext{
*Correspondence: anjupoudelk@gmail.com

${ }^{1}$ Tribhuvan University, Institute of Medicine, Pokhara Nursing Campus,

Pokhara, Nepal

Full list of author information is available at the end of the article
} original author(s) and the source, provide a link to the Creative Commons licence, and indicate if changes were made. The images or other third party material in this article are included in the article's Creative Commons licence, unless indicated otherwise in a credit line to the material. If material is not included in the article's Creative Commons licence and your intended use is not permitted by statutory regulation or exceeds the permitted use, you will need to obtain permission directly from the copyright holder. To view a copy of this licence, visit http://creativecommons.org/licenses/by/4.0/. The Creative Commons Public Domain Dedication waiver (http://creativeco mmons.org/publicdomain/zero/1.0/) applies to the data made available in this article, unless otherwise stated in a credit line to the data. 
depression were the significant predictors of both NSSI and SB. Furthermore, male and adolescents with the history of SB were at risk of NSSI behavior whereas female sex and adolescents with the history of NSSI were at risk of SB.

Keywords: Non suicidal self injury, NSSI, Suicidal behavior, Suicidal attempt, Suicidal ideation

\section{Background}

Non suicidal self injury (NSSI) and suicidal behavior (SB) are the common self harm behaviors among the adolescents and young adults. NSSI refers to an act involving the direct and deliberate destruction of one's body tissue using methods that are not socially or culturally sanctioned and without the intent to kill oneself [1]. The most common examples among adolescents includes the behaviors such as scratching, banging, burning, cutting, self hitting body parts and interfering with wound healing [2-4]. On the other hand suicide refers to self injurious behaviors with the intent to end one's life [5]. Therefore, it is important to differentiate NSSI from suicidal behavior based on recent literatures consensus on "with" and "without" intent to die [6, 7]. Furthermore, suicide related thought and behaviors are classified into: suicide ideation, suicidal plan, suicidal threat and suicide attempt. Suicide ideation is defined as considering or thinking about engaging in behavior intended to end one's life; suicide plan refers to the proposed method of self-injury through which one intends to die; suicide threat refers to any verbal or non-verbal action intended to communicate that suicidal behavior might occur in near future and on the other hand suicide attempt refers to engagement in potentially self-injurious behavior in which there is at least some intent to die $[6,8]$.

A substantial body of research related to NSSI and SB has been conducted in developed countries $[2,9,10]$, highlighting the need of such studies. But it has been neglected entirely in low- and middle-income countries [11] and only few studies from Nepal has acknowledged on this area [12-14]. Most of the previous studies concentrated among clinical populations suggested high prevalence of NSSI among psychiatric patients and its association with various psychiatric problems $[15,16]$ whereas the recent studies highlights a high prevalence of NSSI in nonclinical populations specially community adolescents $[17,18]$. A systematic review including 52 international studies analyzed the prevalence of NSSI in adolescents and reported a rate of $18 \%$ lifetime prevalence of NSSI in community sample [19]. A higher rate i.e. $34 \%$ of adolescents engaging in NSSI at some point in their lives was observed in a study conducted in US [20] whereas other study reported that $29.5 \%$ of adolescents were engaged in NSSI, 7.1 to $8.9 \%$ had elevated levels of suicidal ideation (SI), and $3.3 \%$ of adolescents had suicidal attempt (SA) in the past year [21]. Donath et al. [9] also reported a lifetime prevalence rate of SI 36.6\%, SA $7.6 \%$ and 1 year prevalence of direct self injurious behavior $17.8 \%$ in a representative sample of German students. In a pooled analysis of the Global School-based Student Health Survey (GSHS) across 59 low-income and middleincome countries, the prevalence of SI and SA was found to be 16.9 and $17.0 \%$ respectively, highest in the African region and lowest in the Southeast Asia region [22]. GSHS in Nepal reported the prevalence of SI $13.6 \%$ and SA $10.3 \%$ [13].

NSSI has been associated with a broad array of selfreported functions, including emotion-regulation, selfpunishment or communication of distress [2, 23-26]. Therefore, this behavior is distinguished from SA by the absence of a conscious desire to die. Although NSSI is distinct from SA, some studies indicate that $50-75 \%$ of those individuals with a history of NSSI also have made SA [27, 28]. Numbers of other studies have also shown that NSSI is associated with SB and it is a significant predictor of subsequent NSSI and SA [10, 21, 29-34]. Among 2131 middle school Chinese adolescents, the lifetime prevalence of NSSI and SA was 23.2 and 3.2\% respectively while the co-occurrence of these two behaviors was reported by $2.3 \%$ [33]. Furthermore, it has been suggested that high frequencies of NSSI incidents were associated with a significant increase in risk of SI and SA. Each additional unit increase in reported NSSI was associated with a seven-fold increased likelihood of future SA [21]. Anestis et al. [34] also found that $33.6 \%$ of individuals with prior history of NSSI had ever attempted suicide compared to only $2.5 \%$ of individuals with no prior history of NSSI. The frequent observations of the coexistence of NSSI and SB highlight the essence of assessment of the nature of the link between these two types of behavior. In addition, it is important to underline the factors that differentiate adolescents engaging in NSSI from SA since not all the adolescents who engage in NSSI attempt suicide, and not all the individuals who attempt suicide engage in NSSI.

Despite sound knowledge on human psychology and continuous advancement in neurosciences, suicidal behaviors are difficult to understand [35]. Scientific evidences highlight the role of genetics, various stressors, the hypothalamic-pituitary-adrenal stress-response system, the involvement of the monoaminergic neurotransmitter systems, the lipid profile, neuro-immunological biomarkers, the brain-derived neurotrophic factor and 
other neuromodulators on the complex link between suicidal behavior and depression [36]. Notably, suicidal behavior has been implicated as a co-morbidity of several neuropsychiatric disorders. Recent articles, reporting individual cases have also illustrated the link between depression and suicidal behaviors [37, 38]. Moreover, studies have shown clear association between depressive symptoms and NSSI in adolescents and young adults, both in community [3, 39] and clinical samples [27, 39]. Depression, anxiety, NSSI history, female gender and younger age are often reported as the predictor of NSSI $[40,41]$. Similarly, depressive disorders and NSSI history are the strongest risk factor for SI and SA [30, 41-43]. The adolescents with a history of both attempted suicide and NSSI generally experience more psychological symptoms than adolescents who have engaged in only one type of self-injury [44, 45]. SA and SA plus NSSI group are significantly more likely to be diagnosed with major depressive disorder than only NSSI group [39, 46]. Similarly, Brausch et al. also reported that NSSI group have fewer depressive symptoms, lower SI, and greater selfesteem (SE) than the group that also had attempted suicide [47].

NSSI and SB continue to be absolutely devastating problems among children and adolescents. It has been recognized as a public health problem with high burden in low and middle income countries. Despite the increased interest and pursuit of research into NSSI and $\mathrm{SB}$, there exists no reliable estimate of the prevalence of NSSI and SB in the general Nepalese adolescents. Therefore, the objectives of the current study are

- to assess the prevalence of NSSI and suicidal behavior among adolescents.

- to identify the characteristics of NSSI and suicidal behavior among adolescents

- to assess association between NSSI and suicidal behavior

- to identify the predictors of NSSI and suicidal behavior

The study also sought to fulfill the gap in literature related to NSSI and suicide from developing country like Nepal.

\section{Methods}

A cross sectional survey was conducted at selected public and private secondary level schools of Pokhara Metropolitan city, Nepal.

\section{Participants and procedure}

Two stage cluster sampling technique was applied to select representative sample from study population that comprised of 9 to 12 class students. At first, list of the public and private schools and number of students of each class were obtained from District Education Office, Kaski. Number of students in each class ranged from 30 to 50. In initial stage of sampling strategy, to meet the sample size, 5 public and 5 private schools were chosen from among the total secondary level schools (9 to 12 classes), using simple random sampling technique (lottery method). In second stage, intact classrooms from each of chosen school were selected to participate in the study and each student of selected classroom was eligible to participate in the study. The inclusion criteria for the participation in the study were that the students should of grade 9 to12 and willing to participate in the study.

Sample size was calculated by using the formula $\mathrm{n}=\mathrm{z}^{2} \mathrm{pq} / \mathrm{d}^{2}$. According to the study conducted in Kathmandu, Nepal at tertiary care centers, the overall prevalence of lifetime self-harm behavior among secondary level students is $55.6 \%$ [14]. So, using this prevalence with an allowable error of $5 \%$ at a confidence interval of $95 \%$, the sample size was estimated to be 380 . To minimize the design effect, sample was multiplied by 1.5 as cluster sampling technique was adopted. Assuming a nonresponse rate of $20 \%$, calculated sample size was 684 .

A total of 748 questionnaires were distributed to students of selected classrooms and all of them submitted the questionnaires to the researcher (student response rate $=100 \%$ ). Of them, 18 questionnaires missed the important information or were not readable, thus excluded from the study. Finally 730 questionnaires (382 from public schools and 348 from private schools) were included in the analysis.

\section{Measures}

A semi structured self administered questionnaire was used and it consisted of different parts.

\section{Part I}

Socio-demographic questions included participants age, sex, type of school (Public, Private).

\section{Part II}

NSSI was assessed through Functional Assessment of Self Mutilation (FASM) tool [48]. FASM consists of a checklist of 12 types of NSSI, denoted as 'minor NSSI': hitting self, pulling hair, biting self, inserting objects under nails or skin, picking at a wound, and picking areas to draw blood; 'moderate/severe NSSI': cutting/carving, burning, self-tattooing, scraping, and erasing (i.e. using an eraser to rub skin to the point of burning and bleeding) skin [2]. The questionnaire also consists of NSSI additional information questions, and a checklist of potential functions of NSSI. However in this study NSSI functions were not 
assessed. This tool has been used in several studies [2, 24, 27, 49]. The FASM has demonstrated acceptable psychometric properties within adolescent samples, yielding adequate internal consistency ranging from 0.62 to 0.85 for each subscale of functions of NSSI [25].

\section{Part III}

SB was assessed by using Suicidal Behaviors Questionnaire-Revised (SBQ-R). SBQ-R consisted of four items, each assesses different dimension of suicidality: lifetime suicide ideation and / or suicide attempt, frequency of SI over the past 12 months, threats of SA, and self-reported likelihood of SB in the future. Items are scored using a Likert-scale, with between 5 and 7 response choices per item, and are summed for a total score (range 3-18) [50]. Higher score indicates higher levels of suicidality. Furthermore, the cut-off score between suicidal behavior (SB) and non-suicidal behavior for the undergraduate sample is identified as a score of 7 (i.e., a score of 7 or above will be classified as suicidal). The internal consistency coefficients of the SBQ-R were $0.76-0.88$ in the Osman et al. study [50].

\section{Part IV}

Depression was assessed by using Nepali version of the 21- item Beck Depression Inventory (BDI) [51]. The BDI is a commonly used self- measure of depressive severity that includes 21 questions about various symptoms of depression. Each answers being scored on a scale value of 0 to 3 . Total scores can range from 0 to 63 , with higher scores indicating more depression. The standardized cutoff point is: 0-13: minimal depression, 14-19: mild depression, 20-28: moderate depression, 29-63: severe depression. The Nepali version of BDI has excellent psychometric properties (Cronbach's alpha $=0.90$ and 2 week test-retest reliability $=0.84)[51,52]$.

\section{Part $V$}

SE was assessed by Rosenberg Self-esteem scale (RSES). It is a 10-item measure that assesses an individual's overall evaluation of his or her worth or value [53]. Globally, RSES is the most widely used scale to measure SE among adolescents and has been shown to have good reliability. The items are rated using a 4-point likert scale $(0=$ strongly disagree; $3=$ strongly agree). The scoring is obtained by doing the sum of scores according to the ratings assigned to all the items after reverse scoring the negatively worded items and score ranges from 0 to 30 . The score less than 15 indicate a problematic low self esteem. The internal consistency reliability of tool ranges from 0.85 to 0.88 for college samples [53].
Apart from BDI which was available in Nepali language, other tools were translated into Nepali language using standard guideline [54].

\section{Data collection procedure}

Data was collected on August 2019 after getting ethical approval from Ethical Review Board of Nepal Health Research Council (Ref. No 3051). Informed verbal consent was obtained from the school authority after explaining the purpose of the study. One day before data collection the parents/care giver of all selected participants were informed about the study objectives, nature of the survey, participants rights regarding voluntariness and withdrawn form study through a letter sent to home with their child. Parent's permission to include their child in the study was ensured though signature of the parents in the informed consent form. Furthermore, verbal and written informed consent was obtained from the subjects prior to data collection. One-class period (approx. $45 \mathrm{~min}$ ) was provided to fill in the questionnaire. Considering the sensitivity of the issue, the school authority was requested not to be present in the class during the filling in of the questionnaire. However, researcher was available to make clear of any queries if present. Students were assured that the information they provided would remain confidential and thus were encouraged to be truthful in their responses. They were informed that their participation was completely voluntary and they could quit at any time if they feel uneasy to give answer.

\section{Data analysis}

Statistical Package for Social Sciences (Version 20; IBM Corporation, Armonk, NY, USA) was used for data analysis. Normality was verified using Shapiro-Wilk test, and the data were found to be normally distributed $(p>0.05)$. For the detail analysis of the item 1 of SBQ-R question, the sub-categories: suicidal ideation, suicidal plan and suicidal attempt were entered separately. Furthermore, based on the SBQ- $\mathrm{R}$ cut of point (i.e. Suicidal behavior $(\mathrm{SB})$ : total score $\geq 7$ ), adolescents were further categorized into No-NSSI +No SB group, NSSI only group, SB only group and NSSI+SB group. The data was analyzed by using descriptive statistics such as frequency, percentage, mean and standard deviation. For inferential analysis chi-square test was used for categorical variables and ANOVA test for continuous variable. Furthermore, multiple logistic regression was done to identify the predictors of NSSI and SB.

\section{Results}

Among 730 adolescents participated in the study 382 (52.3\%) were from public and 348 (47.7\%) were from private schools. Almost equal percent, 336 (46\%) were male 
and 394 (54\%) were female. The mean age of the participants was $15.85 \pm 1.31$, ranging from 12 to 19 years. They were categorized into early adolescents (10-14 years) 107 (14.7\%) and late adolescents (15-19years) 623 (85.3\%).

\section{NSSI behavior of adolescents}

Regarding behavioral characteristics, nearly half of the sample $327(44.8 \%)$ reported a history of NSSI in past 1 year. Furthermore, $25.8 \%(n=188)$ of the overall sample engaged in minor NSSI only and 3.42\% $(n=25)$ engaged in at least one act of moderate/severe NSSI. Twenty seven percent of self-injurers $(n=87)$ reported engaging in only one type of NSSI in the past year, while $66 \%$ $(n=217)$ of self-injurers endorsed engaging in two to five different types of NSSI, and 7\% $(n=23)$ endorsed six or more different types of NSSI. The mean number of type of NSSI performed was $2.63 \pm 1.71$ (median $=2.0$, mode $=2.0$, range 1-10). Among those adolescents who engage in NSSI in the past year, the average number of incident was $9.12(\mathrm{SD}=9.95$, median $=6 \cdot 0$, mode $=1 \cdot 0$, range $=1-102)$ (Table 1$)$.

The type of NSSI method used were picking at wound (27.3\%), biting self (20.3\%), pulling hair out (11.8\%), cutting oneself (11.1\%), tattoing $(9.6 \%)$, hitting self on purpose $(9.2 \%)$, inserting objects under nails and skin $(8.1 \%)$, picking areas of own body to the point of drawing blood (7.5\%), erased skin (4.2\%), burning skin (3.4\%) and scraping own skin (2.3\%). Regarding frequency of behavior, the most frequently reported forms of NSSI were also picking at the wound, biting self, pulling hair out. Of moderate to severe NSSI giving self tattoo and cutting on skin was common.

Boys (52.6\%) were more likely to be engaged in NSSI than girls $(47.4 \%)\left(\chi^{2}=10.298, p=0.002\right)$. Similarly, adolescents studying in private schools (53.2\%) reported more NSSI behavior than adolescents of public schools $(37.2 \%)\left(\chi^{2}=10.298, p=0.002\right)$. None of the adolescents reported engaging in NSSI while taking drugs or alcohol, and the majority of them (75\%) reported little or no pain, with the remaining $4 \%$ reported severe pain. The mean age of first NSSI incident was $13.57 \pm 1.71$ years and ranged from 10 to 17 years. Seventeen percent $(n=56)$ of the self-injurers reported receiving medical treatment as a result of their self-injurious behavior.

\section{Suicidal behavior of adolescents}

Among 730 adolescents who completed the SBQ-R questionnaire, 131 (17.9\%) had SB (as defined by SBQ-R, a total score $\geq 7)$. Similarly, 120 (16.4\%) had mild depression, 95 (13.0\%) had moderate depression and 75 (10.3\%) had severe depression. Regarding SE 75 (10.3\%) had low SE and 655 (89.7\%) had high SE (Table 1).

Furthermore, the percentage of participants who reported past SI, past suicidal plans (SP) and past SA were also calculated based on Item 1 of the SBQ-R. The lifetime prevalence of SI, SP an and SA was, 76(10.4\%), $58(7.9 \%)$ and $33(4.5 \%)$ respectively. Similarly, regarding frequency of SI in the past 1 year, $76(10.4 \%)$ had only once, $50(6.8 \%)$ had twice, $16(2.2 \%)$ had 3 to 4 times and $17(2.3 \%)$ had 5 or more times SI in a year. One hundred

Table 1 Behavioral characteristics of adolescents

\begin{tabular}{|c|c|c|c|c|}
\hline & & & & \\
\hline Variables & Category & Number & $\%$ & $\mathrm{M} \pm \mathrm{SD}$ ( $\mathrm{R}=$ Range $)$ \\
\hline \multirow[t]{4}{*}{ NSSI behavior } & No NSSI & 403 & 55.2 & \\
\hline & Minor NSSI only & 188 & 25.8 & \\
\hline & Moderate /Severe NSSI only & 25 & 3.42 & \\
\hline & Both type of NSSI & 114 & 15.6 & \\
\hline \multirow[t]{3}{*}{ Method of NSSI Performed $(n=327)$} & Only one type & 87 & 27.0 & $2.63 \pm 1.71(R=1-10)$ \\
\hline & Two to five type & 217 & 66.0 & \\
\hline & Six or more type & 23 & 7.0 & \\
\hline Frequency of NSSI performed $(n=327)$ & & & & $9.12 \pm 9.95($ Range $=1-102)$ \\
\hline \multirow[t]{2}{*}{ Suicidal Behavior } & No Suicidal Behavior & 599 & 82.1 & $4.44 \pm 2.30(R=3-13)$ \\
\hline & Suicidal Behavior & 131 & 17.9 & \\
\hline \multirow[t]{4}{*}{ Depression } & Minimal range & 440 & 60.3 & $13.36 \pm 10.31(R=0-53)$ \\
\hline & Mild depression & 120 & 16.4 & \\
\hline & Moderate depression & 95 & 13.0 & \\
\hline & Severe depression & 75 & 10.3 & \\
\hline \multirow[t]{2}{*}{ Self-esteem } & Low self-esteem & 75 & 10.3 & $24.53 \pm 7.24(R=0-30)$ \\
\hline & High self-esteem & 655 & 89.7 & \\
\hline
\end{tabular}


sixty three (22.3\%) adolescents had threat of SA or they told to other people as they were going to commit suicide. Out of those, 103 (63.2\%) adolescents told once and $60(36.8 \%)$ adolescents told more than once to others. The likelihood of SB in future was reported only by 3 (0.4\%) adolescents (Table 2).

Regarding sex differences female were significantly higher in life time prevalence of SB than male $\left(\chi^{2}=30.26\right.$, $p=0.001)$. No significant differences were noted between private and public schools in SB.

\section{Association between NSSI and suicidal behavior}

Simple Chi-square tests indicated that NSSI was significantly associated with SB $\left(\chi^{2}=58.16, P<.001\right)$. Of those who had SB, $74.8 \%$ had also engaged in NSSI and of those who reported NSSI, $30.0 \%$ also had the history of SB. Separate analysis of the elements of SB revealed that lifetime prevalence was significantly higher among NSSI

Table 2 Magnitude of Suicidal Behavior among adolescents

\begin{tabular}{|c|c|c|c|}
\hline \multirow[b]{2}{*}{ Variables } & \multirow[b]{2}{*}{ Category } & \multicolumn{2}{|c|}{$n=730$} \\
\hline & & $\mathrm{n}$ & Percent \\
\hline \multirow{4}{*}{$\begin{array}{l}\text { Life time suicidal ideation, intent } \\
\text { and/or attempts }\end{array}$} & Never & 563 & 77.1 \\
\hline & Suicidal ideation & 76 & 10.4 \\
\hline & Suicidal Plan & 58 & 7.9 \\
\hline & Suicide attempts & 33 & 4.5 \\
\hline \multirow{5}{*}{$\begin{array}{l}\text { Frequency of suicidal ideation } \\
\text { in the } \\
\text { past } 1 \text { year }\end{array}$} & Never & 571 & 78.2 \\
\hline & Once & 76 & 10.4 \\
\hline & Twice & 50 & 6.8 \\
\hline & 3-4 times & 16 & 2.2 \\
\hline & Always ( $\geq 5$ times) & 17 & 2.3 \\
\hline \multirow{3}{*}{ Suicidal threats } & Never & 567 & 77.6 \\
\hline & Once & 103 & 14.1 \\
\hline & Twice and more & 60 & 8.2 \\
\hline \multirow{5}{*}{$\begin{array}{l}\text { Likely hood of suicide in the } \\
\text { future }\end{array}$} & Never & 564 & 77.3 \\
\hline & No chance at all & 94 & 12.9 \\
\hline & Rather unlikely & 63 & 8.6 \\
\hline & Unlikely & 6 & 0.8 \\
\hline & Likely & 3 & 0.4 \\
\hline
\end{tabular}

adolescents than No-NSSI adolescents for suicidal ideation (17.4\% vs 4.7\%; OR: 4.2 [95\%CI, 2.4-7.3]; $P<.001)$ and plan (8.6\% vs 7.4\%; OR, 1.1 [95\%CI, 0.6-1.9]; $P<.001)$ and attempt (8.0\% vs 1.7\%); OR, 4.8 [95\%CI, 2.0-11.4]; $P<.001$ ) (Table 3).

\section{Group differences}

Based on the adolescent's NSSI and SB they were categorized into different groups. The No-NSSI +No SB group included $370(50.6 \%)$ adolescents, the NSSI only group had 229 (31.3\%) adolescents, SB only group had 33 (4.5\%) adolescents and NSSI + SB group had 98 (13.4\%) adolescents. Significant differences emerged between groups in terms of all demographic and psychological characteristics. SB only group were predominantly female and from public school compared to three other groups. Furthermore, all the four groups were mostly late age adolescents (15-19 years), and the difference was significant (Table 4).

In addition, data were analyzed using a one- way ANOVA with self-harm group as independent variable and depression and self-esteem as dependent variable. The NSSI+SB group were significantly more depressed and had lower level of self-esteem than NSSI only, SB only and No-NSSI +No SB groups (Table 4).

\section{Logistic regression to identify the predictors of NSSI and suicidal behaviors}

Logistic regressions identified the four significant predictors of NSSI behavior: sex, SE, depression and SB. Dependent variable, NSSI behavior had two categories: No NSSI and NSSI adolescents. Female adolescents and those with higher SE were less likely to perform NSSI behavior. Similarly, compared to those who do not have suicidal thought, adolescents who have SI were 4.6 times, and those who had attempted suicide were 4.2 times higher risk of NSSI behavior. Furthermore, adolescents who had moderate to severe depression were 2.6 times higher risk of NSSI behavior as compared to minimal to mildly depressed adolescents (Table 5).

To identify the predictors of SB, age, sex, selfesteem, depression and NSSI behavior was entered as

Table 3 Association between NSSI and Suicidal Behavior

$n=730$

\begin{tabular}{lllll} 
NSSI behavior & \multicolumn{2}{l}{ Suicidal Behavior } & & \\
\cline { 2 - 5 } & No Suicidal Thought & Suicidal Ideation & Suicidal Plan & Suicidal Attempt \\
\hline No- NSSI & $347(86.1 \%)$ & $19(4.7 \%)$ & $30(7.4 \%)$ & $7(1.7 \%)$ \\
NSSI & $216(66.1 \%)$ & $57(17.4 \%)$ & $28(8.6 \%)$ & $26(8.0 \%)$ \\
OR (95\%Cl) & $3.1(2.2-4.5)$ & $4.2(2.4-7.3)$ & $1.1(0.6-1.9)$ & $4.8(2.0-11.4)$ \\
P-value & $<.001$ & $<.001$ & $<.001$ & $<.001$ \\
\hline
\end{tabular}


Table 4 Characteristics of NSSI and SA adolescents

\begin{tabular}{|c|c|c|c|c|c|c|c|c|c|c|}
\hline Dichotomous Variable & $\begin{array}{l}\text { No-NSSI + No SB } \\
n=370 \\
n\end{array}$ & $\%$ & $\begin{array}{l}\text { NSSI only } \\
n=229 \\
n\end{array}$ & $\%$ & $\begin{array}{l}\text { SB Only } \\
N=33 \\
\mathrm{n}\end{array}$ & $\%$ & $\begin{array}{l}\mathrm{NSSI}+\mathrm{SB} \\
n=98 \\
\mathrm{n}\end{array}$ & $\%$ & Chi-square test ( $\left.x^{2}\right)$ & $p$-value \\
\hline Female & 213 & 57.6 & 94 & 41.0 & 26 & 78.8 & 61 & 62.2 & 28.20 & $<.001^{*}$ \\
\hline Public School & 217 & 58.6 & 93 & 40.6 & 23 & 69.7 & 49 & 50.0 & 22.73 & $<.001^{*}$ \\
\hline Late aged adolescent & 300 & 81.1 & 208 & 90.8 & 30 & 90.9 & 85 & 86.7 & 11.85 & $.008^{*}$ \\
\hline Continuous Variable & Mean & (SD) & Mean & (SD) & Mean & (SD) & Mean & (SD) & ANOVA test $(F)$ & $p$-value \\
\hline Depression & 10.08 & 8.59 & 13.57 & 9.11 & 15.54 & 7.64 & 24.52 & 11.61 & 64.59 & $<.001^{*}$ \\
\hline Self-esteem & 26.24 & 5.76 & 23.79 & 7.31 & 23.36 & 9.16 & 20.20 & 9.07 & 21.25 & $<.001^{*}$ \\
\hline
\end{tabular}

NSSI Non-suicidal self injury, SB Suicidal behavior, ${ }^{*} p$-value significance at $\leq 0.05$ level

Table 5 Predictors of NSSI behavior

\begin{tabular}{|c|c|c|c|c|c|}
\hline Predictor variable & B & SE & Odd ratio & $P$ value & $95.0 \% \mathrm{Cl}$ for odds ratio \\
\hline \multicolumn{6}{|l|}{ Age } \\
\hline \multicolumn{6}{|l|}{ Early adolescents (Reference) } \\
\hline Late adolescents & 0.347 & 0.241 & 1.415 & 0.150 & 0.882 to 2.270 \\
\hline \multicolumn{6}{|l|}{ Sex } \\
\hline \multicolumn{6}{|l|}{ Male (reference) } \\
\hline Female & -0.858 & 0.172 & 0.424 & $<0.001$ & 0.302 to 0.594 \\
\hline \multicolumn{6}{|l|}{ Suicidal behavior } \\
\hline No Suicidal Thought (reference) & & & 4.648 & $<0.001$ & 2.608 to 8.282 \\
\hline Suicidal Ideation & 1.536 & 0.295 & 1.209 & 0.542 & 0.657 to 2.224 \\
\hline Suicidal Plan & 0.190 & 0.311 & 4.236 & 0.002 & 1.517 to 10.460 \\
\hline Suicidal Attempt & 1.444 & 0.461 & & & \\
\hline \multicolumn{6}{|l|}{ Depression } \\
\hline \multicolumn{6}{|c|}{ Minimal to Mild depression (reference) } \\
\hline Moderate to Severe depression & 0.976 & 0.212 & 2.655 & $<0.001$ & 1.752 to 4.022 \\
\hline \multicolumn{6}{|l|}{ Self-esteem } \\
\hline \multicolumn{6}{|l|}{ Low self-esteem (reference } \\
\hline High self-esteem & -0.747 & 0.290 & 0.474 & 0.010 & 0.268 to 0.837 \\
\hline
\end{tabular}

independent variables. Based on SBQ-R cut off point, SB was defined into two group: No SB and SB. Sex, SE, depression and NSSI behavior were the independent predictors of SB. Female adolescents compared to male adolescents were 1.7 times at risk of SB. Similarly, compared to those adolescents who do not perform NSSI, adolescents who perform only minor type of NSSI were 2.4 times, moderate to severe type of NSSI performing adolescents 8.5 times and those who perform both type of NSSI were 5.3 times higher risk of SB. Furthermore, adolescents with higher SE were less likely to exhibit SB than adolescents having lower SE and adolescents who had moderate to severe depression were 3.8 times higher risk of SB as compared to minimal to mildly depressed adolescents (Table 6).

\section{Discussion}

By definition, both NSSI and SA involve intentional harm to oneself but, unlike suicide attempts, NSSI does not involve intent to die. NSSI is a common but often hidden behavior, especially among adolescents. Nearly half of the sample $44.8 \%$ reported a history of NSSI in past 1 year. This proportion is fairly consistent with other studies [2, 55]. A previous study from Nepal also found higher rate of self harm behavior among adolescents with lifetime prevalence of $55.6 \%$ [14]. Similarly, a study with similar type of sample from US also reported that approximately $34 \%$ of the adolescents were engaged in some form of NSSI at some point in their lives, with $16 \%$ of the overall sample reporting evidence of repetitive NSSI in the past 6 months [20]. However, the present study prevalence rate is generally higher than earlier studies of adolescent 
Table 6 Predictors of Suicidal behavior

\begin{tabular}{|c|c|c|c|c|c|}
\hline & & & & & \\
\hline Predictor variable & B & SE & Odd ratio & $P$ value & $95.0 \% \mathrm{Cl}$ for odds ratio \\
\hline \multicolumn{6}{|l|}{ Age } \\
\hline Early adolescents (Reference) & & & & & 0.492 to 1.791 \\
\hline Late adolescents & -0.06 & 0.32 & 0.939 & 0.849 & \\
\hline \multicolumn{6}{|l|}{ Sex } \\
\hline \multicolumn{6}{|l|}{ Male (reference) } \\
\hline Female & 0.55 & 0.237 & 1.733 & 0.020 & 1.090 to 2.757 \\
\hline \multicolumn{6}{|l|}{ NSSI behavior } \\
\hline \multicolumn{6}{|l|}{ No NSSI (reference) } \\
\hline Minor NSSI & 0.883 & 0.274 & 2.418 & 0.001 & 1.414 to 4.134 \\
\hline Moderate to Severe NSSI & 2.148 & 0.485 & 8.567 & $<0.001$ & 3.310 to 22.170 \\
\hline Both NSSI (Minor+Moderate to Severe NSSI) & 1.672 & 0.294 & 5.321 & $<0.001$ & 2.993 to 9.459 \\
\hline \multicolumn{6}{|l|}{ Depression } \\
\hline \multicolumn{6}{|l|}{ Minimal to Mild depression (reference) } \\
\hline Moderate to Severe depression & 1.356 & 0.234 & 3.882 & $<0.001$ & 2.452 to 6.147 \\
\hline \multicolumn{6}{|l|}{ Self-esteem } \\
\hline \multicolumn{6}{|l|}{ Low self-esteem (reference) } \\
\hline High self-esteem & -0.821 & 0.304 & 0.440 & 0.007 & 0.242 to 0.798 \\
\hline
\end{tabular}

community samples $[9,17,18,41,47]$. The difference in prevalence rates might be due to differences in the cultural background of the sample, as well as use of different tools to assess self injuring method.

Furthermore, $66 \%$ of self-injurers endorsed engaging in two to five different types of NSSI, and 7\% endorsed six or more different types of NSSI which is almost similar to the study by Lloyd-Richardson et al. [2]. Boys were more likely to be engaged in NSSI than girls. However some other studies indicated higher prevalence in girls [21, 56] and some Nepalese and Chinese adolescents did not reveal significant gender differences in rates of self-harm behavior [14, 17]. The most frequently reported forms of NSSI were picking at the wound, biting self and pulling hair out. Self tattooing and cutting on skin were common form of moderate to severe type of NSSI. Study conducted by Giri in Nepal also found scratching the skin, tattooing, preventing wounds from healing and cutting skin as the commonly chosen method of NSSI [14]. Chinese adolescents also reported hitting, pinching, pulling hair and biting, the frequently occurring NSSI behavior [17]. However some studies have suggested picking at the wound is clinically insignificant behavior [2] and biting self is a socially acceptable and normative behavior [57].

Suicide is one of the leading causes of death among adolescents around the world. In this study the life time prevalence of SB was $17.9 \%$. In addition, the lifetime prevalence of SI, SP and SA were, 10.4, 7.9 and $4.5 \%$ respectively. Almost similar finding has been reported with the 1 year prevalence rate of 8.8 and $3.5 \%$ for SI and SA respectively in a study conducted in China [41]. However the prevalence rate found in our study is slightly lower than that reported by a global school health survey in Nepal which reported that nearly $14 \%$ of school students had SI while 10.3\% had attempted suicide [13]. Global variation can be observed with prevalence of SI and SA, 4.9 and 6.7\% in Bangladesh [58] and 11.6 and $11.3 \%$ in Bhutan [59] respectively. The heterogeneity across countries might be due to the effect of various risk factors associated with SB. Regarding sex differences female were significantly higher in life time prevalence of SB than male. It has been supported by many studies [13, 22, 33].

The present study found the significant association between NSSI and SB. NSSI was significantly associated with the increase odds of SI, SP and SA (OR: 4.2, 1.1 and 4.8 respectively). Of those who were engaged in NSSI, $8.0 \%$ of the adolescents had attempted suicide, which is significantly higher than that of people who were engaged in No- NSSI (1.7\%). Furthermore, $13.4 \%$ of the overall sample reported co-occurrence of both NSSI and SB. Of those who had SB, $74.8 \%$ had also engaged in NSSI and of those who reported NSSI, 30\% also had the history of SB. A high co-occurrence of NSSI and SA was observed among outpatient samples of adolescents where $37 \%$ of adolescents with a history of NSSI also reported having made at least one SA $[29,39]$. A study by Nock et al. reported that $55-70 \%$ of adolescents with NSSI also 
had history of attempted suicide [29]. Moreover, a recent study found $7.7 \%$ lifetime prevalence of co-occurrence of NSSI and SB, among those with NSSI, 39.6\% endorsed $\mathrm{SB}$, and $66.3 \%$ of those with SB reported NSSI [60]. Consistent with the present study, Kiekens et al. [56] reported that NSSI was associated with increased odds of subsequent suicide ideation $(\mathrm{OR}=2.8)$, plan $(\mathrm{OR}=3.0)$, and attempt $(\mathrm{OR}=5.5)$. These findings extend the previous work and provide evidence on co-occurrence and association between NSSI and SB [21, 31, 32, 41, 44, 56].

Despite the above evidence that NSSI and SB co-occur, these behaviors also differ in many ways in some characteristics $[28,29,31,33,39,44-47,61]$. In this study, significant differences were found between four groups (No NSSI and No SB, NSSI only, SB only, NSSI+SB) on age, sex, type of school, depression and self-esteem. SB only group and NSSI+SB group were predominantly female and from public school compared to NSSI only group. In addition, NSSI+SB group were significantly more depressed and had lower level of self-esteem than NSSI only, SB only and No-NSSI +No SB groups. Regarding gender, the finding has been contradicted by previous studies where the groups were predominated by female gender but the difference was not significant [39, 47] whereas significant difference was noted on a study conducted by Liang et al. [33]. Furthermore, in line with this study, the previous study found no self harm group reporting lower level of risk factors (hopelessness) and highest level of protective factor (self-esteem) compared to NSSI and NSSI+SA groups [47]. The other study also identified that adolescents in NSSI+SA group and SA only group were more likely to meet criteria for a major depressive disorder than NSSI only group [39]. The current study findings provide evidence that adolescents with both type of behavior are at greater risk of having sever form of psychological symptoms than adolescents with only one type of self harm behavior.

Furthermore, the study identified low self-esteem, moderate to severe form of depression, history of SI, history of SA and male gender as the significant predictors of NSSI, which differentiates adolescents with NSSI from No NSSI group. A study by Garisch et al. also reported that higher level of depression and lower self esteem are significantly associated with NSSI [55]. In addition, a recent review [40] highlighted depressive symptoms, suicidality and psychological distress as the important predictors of NSSI and our result further supports this finding. The same study [40] found female gender as the predictor of NSSI, however our study did not support this finding. NSSI theories proposed that people who engage in NSSI have particularly high levels of emotion dysregulation, and these feelings drive them to engage in NSSI as a way to improve their mood [62]. Moreover, prior history of suicidal thought and behavior has been found as the significant risk factor of NSSI $[63,64]$. In addition, empirical evidence has demonstrated that NSSI is under-taken by some to alleviate negative emotions (such as low self-esteem) and may be used in times of difficulty in a person's life [65]. Regarding gender in contrast to previous studies $[30,64]$ the current study revealed male as the significant predictor of NSSI.

Similarly, the lower level of self esteem, moderate to severe depression, female gender, minor and moderate to severe form of NSSI and engagement in both type of NSSI are the significant predictors of SB. These variables significantly differentiate the individuals with SB from without SB. Most of the previous studies suggest that NSSI is a strong risk factor for future SA $[10,11,27$, 30]. Nock et al. suggests that adolescents who use more varied methods to injure themselves are more likely to have a history of SA [27]. In addition, NSSI thought and higher frequencies of NSSI concurrently are associated with higher levels of suicide ideation and a history of SA [2, 3, 27, 28, 56]. Moderate to severe form of NSSI is associated with increased suicidal thoughts and behaviors compared to mild NSSI $[2,41]$ which is consistent with our study finding. Furthermore, among mental disorders, major depressive disorder is the strongest predictors of suicide and SB $[42,66]$. In addition, a meta-analysis of the longitudinal studies identified low level of self-esteem as a significant risk factor of SA in adolescents and young adults [67].

The finding of this study has to be considered with reference to its limitations. The students who are more likely to have risk behaviors such as school not going students and drop out students were missed in the study which limits the generalizability of our findings. Furthermore, the study findings depend on the response of adolescents from self-administered questionnaire that might result in recall bias and unwillingness to provide their personnel information might have lead to either over reporting or under reporting of information. Moreover, there might be social desirability bias, since the existing stigma surrounding SB in culturally diversified Nepalese societies might have caused an underreporting of the conditions. In addition to this, the cross-sectional nature of the study prevents establishing a causal relationship between the variables. The lower level of self esteem and depression were either cause or consequences of NSSI and SB has not been identified. Thus, to solve this problem and identify the causal relationships, longitudinal and experimental studies need to be done. 


\section{Conclusion}

The prevalence of both NSSI and SB is high in adolescents. Despite the differences between NSSI and SB, a significant number of adolescents reported a history of both behaviors. Moreover, two of the strongest NSSI risk factors, lower level of self-esteem and depression were also the significant risk factors of SB. Furthermore, Male gender and history of SI and SA is the significant predictor of NSSI behavior. Similarly, female gender and adolescents with the history of NSSI behavior are at risk of SB. Thus the finding reinforces the importance of assessment of various risk behavior among the adolescents so that prevalence of NSSI and SB can be minimized.

\section{Implication of the study}

Although there are plenty of study assessing NSSI behavior among adolescents from the USA, Canada, Australia and UK, data on adolescent NSSI are scarce from developing country like Nepal. Despite the above limitations, as per the researcher's knowledge this is the first study to assess NSSI behavior among adolescents in Nepal. The study identified that large number of adolescents with risk behavior are in hidden form, that they need to be identified and appropriate intervention should be done. The finding provides valuable information to parents and teachers to assess the adolescent's behavior and examine the psychological health periodically so that risk behavior like NSSI and suicide can be prevented by adopting appropriate preventive strategies. The study findings could be useful for policy makers in designing appropriate preventive strategies for suicide prevention programs. Furthermore, the significant association found between NSSI and SB; and higher level of depression and low level of self-esteem in NSSI+SB group emphasizes the potential importance of identifying and treating adolescents with a history of NSSI, and continuous assessment of adolescents' mental health status. In addition, sex, selfesteem and depression were identified as the significant predictors of NSSI and suicidal behavior (which includes suicidal ideation, suicidal plan and suicidal attempt), that highlight the importance of consideration of socio-demographic characteristics and psychological factors on the occurrence of these negative outcomes. Understanding the reasons of NSSI is crucial for treatment; and future research needs to elaborate further on previous work. Furthermore, studies exploring the association of selfesteem with NSSI and SB among adolescents would be warranted as there is scare of literatures on this topic.

\section{Abbreviations}

NSSI: Non Suicidal Self Injury; FASM: Functional Assessment of Self Mutilation; SBQ-R: Suicidal Behaviors Questionnaire-Revised; BDI: Beck Depression
Inventory; RSES: Rosenberg Self-Esteem Scale; SB: Suicidal Behaviour; SA: Suicidal Attempt; SP: Suicidal Plan; SI: Suicidal Ideation; SE: Self-esteem; GSHS: Global School-based Student Health Survey.

\section{Acknowledgements}

We would like to thank Nepal Health Research Council for accepting our proposal and providing ethical clearance. We would like to extend our thanks to District Education Office, Kaski, Nepal for providing us the list of school of Pokhara Metropolitan City. Similarly, our sincere gratitude goes to principals of different schools for helping us with setting to conduct this study. We owe our vote of thanks to all the students who participated in this study.

\section{Authors' contributions}

$A P$ and $A L$ were involved with the design of the study, and wrote the first draft of the manuscript. AP, AL, KRM and GPK collected data. AP and GPK performed statistical analysis revised manuscript for important intellectual content. All authors read, edited and approved the final manuscript.

\section{Funding}

None.

\section{Availability of data and materials}

The dataset supporting the conclusions of this study is included within the article. Regarding different tools used in this study, it is a copyright tool. The translated Nepali version of this tool are however available from the corresponding author upon request and with permission obtained from copyright owner of the tool.

\section{Declarations}

Ethics approval and consent to participate

This study complied with the Declaration of Helsinki and an ethical clearance was taken from Ethical Review Board of Nepal Health Research Council, Nepal (Ref. No 3051). All the methods were performed in accordance with the relevant guidelines and regulations. Formal permission was obtained from the school authorities and a written informed consent was taken from the students and their parents. They were also informed about the purpose of the study, their voluntariness in participation and no any foreseeable risk and harm in the study.

\section{Consent for publication}

Not applicable.

\section{Competing interests}

The authors declare that they have no competing interests.

\section{Author details}

${ }^{1}$ Tribhuvan University, Institute of Medicine, Pokhara Nursing Campus, Pokhara, Nepal. ${ }^{2}$ Satvik Nepal, Pokhara, Nepal. ${ }^{3}$ Health Directorate, Pokhara, Gandaki Province, Nepal. ${ }^{4}$ Pokhara Academy of Health Sciences, Pokhara, Nepal.

Received: 17 November 2021 Accepted: 4 February 2022

Published online: 09 February 2022

\section{References}

1. Nock MK, Favazza AR. Nonsuicidal self-injury: definition and classification. In: Nock MK, editor. Understanding nonsuicidal self-injury. Origins, assessment and treatment. Washington, DC: American Psychological Association; 2009. p. 9-18.

2. Lloyd-Richardson EE, Perrine N, Dierker L, Kelley ML. Characteristics and functions of non-suicidal self-injury in a community sample of adolescents. Psychol Med. 2007;37:1183-92.

3. Klonsky ED, Olino TM. Identifying clinically distinct subgroups of self-injurers among young adults: a latent class analysis. J Consult Clin Psychol. 2008;76(1):22-7. 
4. Kuentzel JG, Arble E, Boutros N, Chugani D, Barnett D. Nonsuicidal self-injury in an ethnically diverse college sample. Am J Orthop. 2012:82(3):291-7.

5. Nock MK, Borges G, Bromet EJ, Cha CB, Kessler RC, Lee S. Suicide and suicidal behavior. Epidemiol Rev. 2008;30:133-4.

6. Silverman MM, Berman AL, Sanddal ND, O'carroll PW, Joiner TE Jr. Rebuilding the tower of babel: a revised nomenclature for the study of suicide and suicidal behaviors. Part 2: suicide-related ideations, communications, and behaviors. Suicide Life-Threat Behav. 2007;37(3):264-77.

7. Hargus E, Hawton K, Rodham K. Distinguishing between subgroups of adolescents who self-harm. Suicide Life Threat Behav. 2009;39:518-37. https://doi.org/10.1521/suli.2009.39.5.518.

8. Silverman MM, Berman AL, Sanddal ND, O'carroll PW, Joiner TE Jr. Rebuilding the tower of babel: a revised nomenclature for the study of suicide and suicidal behaviors. Part 1: background, rationale, and methodology. Suicide Life Threat Behav. 2007;37(3):248-63.

9. Donath C, Bergmann MC, Kliem S, Hillemacher T, Baier D. Epidemiology of suicidal ideation, suicide attempts, and direct self-injurious behavior in adolescents with a migration background: a representative study. BMC Pediatr. 2019;19(1):45.

10. Mars B, Heron J, Klonsky ED, Moran P, O'Connor RC, Tilling K, et al. Predictors of future suicide attempt among adolescents with suicidal thoughts or non-suicidal self-harm: a population-based birth cohort study. Lancet Psychiatry. 2019;6(4):327-37.

11. Aggarwal S, Berk M. Nonsuicidal self-injury in Indian adolescents: nonexistent or unacknowledged? Int J Soc Psychiatry. 2015;61(5):516-7.

12. Marahatta K, Samuel R, Sharma P, Dixit L, Shrestha BR. Suicide burden and prevention in Nepal: the need for a national strategy. WHO South East Asia J Public Health. 2017;6(1):45.

13. Pandey AR, Bista B, Dhungana RR, Aryal KK, Chalise B, Dhimal M. Factors associated with suicidal ideation and suicidal attempts among adolescent students in Nepal: findings from global school-based students health survey. PLoS One. 2019;14(4):e0210383.

14. Giri A. Self-harm behavior among adolescent students of higher secondary schools of Kathmandu Valley, Nepal. JHAS. 2020;10(1):52-8.

15. Briere J, Gil E. Self-mutilation in clinical and general population samples: prevalence, correlates, and functions. Am J Orthop. 1998;68:609-20.

16. Cipriano A, Cella S, Cotrufo P. Nonsuicidal self-injury: a systematic review. Front Psychol. 2017;8:1946.

17. Wan $\mathrm{YH}, \mathrm{Hu} \mathrm{CL}$, Hao JH, Sun Y, Tao FB. Deliberate self-harm behaviors in Chinese adolescents and young adults. Eur Child Adolesc Psychiatry. 2011;20:517.

18. Swannell SV, Martin GE, Page A, Hasking P, John ST, NJ. Prevalence of nonsuicidal self-injury in nonclinical samples: systematic review, Meta-analysis and Meta-regression. Suicide Life Threat Behav. 2014;44(3):273-303

19. Muehlenkamp JJ, Claes L, Havertape L, Plener PL. International prevalence of adolescent non-suicidal self-injury and deliberate self-harm. Child Adolesc Psychiatry Ment Health. 2012;6(10).

20. Howe-Martin LS, Murrell AR, Guarnaccia CA. Repetitive nonsuicidal self-injury as experiential avoidance among a community sample of adolescents. J Clin Psychol. 2012;68(7):809-8.

21. Guan K, Fox KR, Prinstein MJ. Nonsuicidal self-injury as a time-invariant predictor of adolescent suicide ideation and attempts in a diverse community sample. J Consult Clin Psychol. 2012;80:842-9.

22. Uddin R, Burton NW, Maple M, Khan SR, Khan AJTLC. A suicidal ideation, suicide planning, and suicide attempts among adolescents in 59 lowincome and middle-income countries: a population-based study. Lancet Child Adolesc Health. 2019;3(4):223-33.

23. Klonsky ED, Victor SE, Saffer BY. Nonsuicidal self-injury: what we know, and what we need to know. Can J Psychiatry. 2014;59(11):565-8.

24. Nock MK, Prinstein MJ. A functional approach to the assessment of selfmutilative behavior. J Consult Clin Psychol. 2004:72:885-90.

25. Nock MK, Prinstein MJ, Sterba SK. Revealing the form and function of self injurious thoughts and behaviors: a real-time ecological assessment study among adolescents and young adults. J Abnorm Psychol. 2009;118(4):816-27.

26. Rodav O, Levy S, Hamdan S. Clinical characteristics and functions of nonsuicide self-injury in youth. Eur Psychiatry. 2014;29(8):503-8.

27. Nock MK, Joiner TE, Gordon KH, Lloyd-Richardson E, Prinstein MJ. Nonsuicidal self-injury among adolescents: diagnostic correlates and relation to suicide attempts. Psychiatry Res. 2006;144:65-72.
28. Andover MS, Gibb BE. Non-suicidal self-injury, attempted suicide, and suicidal intent among psychiatric inpatients. Psychiatry Res. 2010;178:101-5.

29. Asarnow JR, Porta G, Spirito A, Emslie G, Clarke G, Wagner KD, et al. Suicide attempts and nonsuicidal self injury in the treatment of resistant depression in adolescents: findings from the TORDIA study. J Am Acad Child Adolesc Psychiatry. 2011;50:772-81.

30. Wilkinson P, Kelvin R, Roberts C, Dubicka B, Goodyer I. Clinical and psychosocial predictors of suicide attempts and nonsuicidal self-injury in the adolescent depression antidepressants and psychotherapy trial (ADAPT). Am J Psychiatry. 2011;168:495-501.

31. Klonsky ED, May AM, Glenn CR. The relationship between nonsuicidal self- injury and attempted suicide: converging evidence from four samples. J Abnorm Psychol. 2013;122:231-7.

32. Glenn CR, Lanzillo EC, Esposito EC, Santee AC, Nock MK, Auerbach RP. Examining the course of suicidal and nonsuicidal self-injurious thoughts and behaviors in outpatient and inpatient adolescents. J Abnorm Child Psychol. 2017;45(5):971-83.

33. Liang S, Yan J, Zhang T, Zhu C, Situ M, Du N, et al. Differences between non-suicidal self injury and suicide attempt in Chinese adolescents. Asian J Psychiatr. 2014;8:76-83.

34. Anestis MD, Khazem LR, Law KC. How many times and how many ways: the impact of number of nonsuicidal self-injury methods on the relationship between nonsuicidal self-injury frequency and suicidal behavior. Suicide Life Threat Behav. 2014:45(2):164-77.

35. De Berardis D, Fornaro M, Valchera A, Cavuto M, Perna G, Di Nicola $M$, et al. Eradicating suicide at its roots: preclinical bases and clinical evidence of the efficacy of ketamine in the treatment of suicidal behaviors. Int J Mol Sci. 2018;19(10):2888.

36. Orsolini L, Latini R, Pompili M, Serafini G, Volpe U, Vellante F, et al. Understanding the complex of suicide in depression: from research to clinics. Psychiatry Investig. 2020;17(3):207.

37. Kustermann A, Möbius C, Oberstein T, Müller HH, Kornhuber J. Depression and attempted suicide under pregabalin therapy. Ann Gen Psychiatry. 2014;13(1):1-2.

38. Pompili M. Critical appraisal of major depression with suicidal ideation. Ann Gen Psychiatry. 2019;18(1):1-5.

39. Jacobson CM, Muehlenkamp JJ, Miller AL, Turner JB. Psychiatric impairment among adolescents engaging in different types of deliberate self-harm. J Clin Child Adoles Psychiat. 2008;37:363-75.

40. Plener PL, Schumacher TS, Munz LM, Groschwitz RC. The longitudinal course of non-suicidal self-injury and deliberate self-harm: a systematic review of the literature. Borderline Personal Disord Emot Dysregul. 2015;2:2.

41. Tang J, Yu Y, Wu Y, Du Y, Ma Y, Zhu H, et al. Association between nonsuicidal self-injuries and suicide attempts in Chinese adolescents and college students: a cross-section study. PLoS One. 2011;6(4):e17977.

42. Goldston DB, Daniel SS, Erkanli A, Reboussin BA, Mayfield A, Frazier PH, et al. Psychiatric diagnoses as contemporaneous risk factors for suicide attempts among adolescents and young adults: developmental changes. J Consult Clin Psychol. 2009;77:281-90.

43. Gould MS, Greenberg T, Velting DM, Shaffer D. Youth suicide risk and preventive interventions: a review of the past 10 years. J Am Acad Child Adolesc Psychiatry. 2003;42(4):386-405.

44. Andover MS, Morris BW, Wren A, Bruzzese ME. The co-occurrence of non-suicidal self-injury and attempted suicide among adolescents: distinguishing risk factors and psychosocial correlates. Child Adolesc Psychiatry Ment Health. 2012;6:11.

45. Bae Y, Seong Y, Kim SH, Kim S. Clinical characteristics of non-suicidal self-injury and suicide attempts among psychiatric patients in Korea: a retrospective chart review. Psychiatry Investig. 2020;17(4):320.

46. Dougherty DM, Mathias CW, Marsh-Richard DM, Prevette KN, Dawes MA, Hatzis ES, et al. Impulsivity and clinical symptoms among adolescents with non-suicidal self-injury with or without attempted suicide. Psychiatry Res. 2009;169:22-7.

47. Brausch AM, Gutierrez PM. Differences in non-suicidal self-injury and suicide attempts in adolescents. J Youth Adolesc. 2010;39(3):233-42.

48. Lloyd E, Kelley M, Hope T. Self-mutilation in a community sample of adolescents: descriptive characteristics and provisional prevalence rates. New Orleans: Annual meeting of the Society for Behavioral Medicine; 1997. 
49. Yates TM, Luthar SS, Tracy AJ. Nonsuicidal self-injury among privileged youths: longitudinal and cross-sectional approaches to developmental process. J Consult Clin Psychol. 2008;76(1):52-62.

50. Osman A, Bagge CL, Gutierrez PM, Konick LC, Kopper BA, Barrios FX. The suicidal behaviors questionnaire-revised (SBQ-R): validation with clinical and nonclinical samples. Assessment. 2001;8:443-54.

51. Kohrt BA, Kunz RD, Koirala NR, Sharma VD, Nepal MK. Validation of a Nepali version of the Beck depression inventory. Nepalese J Psychiatry. 2002;2(4):123-30

52. Kohrt BA, Speckman RA, Kunz RD, Baldwin UL, Upadhaya N, Acharya NR, et al. Culture in psychiatric epidemiology: using ethnography and multiple mediator models to assess the relationship of caste with depression and anxiety in Nepal. Ann Hum Biol. 2009;36(3):261-80.

53. Rosenberg M. Society and adolescent self-image. Princeton: Princeton University Press; 1965.

54. Sousa VD, Rojjanasrirat W. Translation, adaptation and validation of instruments or scales for use in cross-cultural health care research: a clear and user-friendly guideline. J Eval Clin Pract. 2011;17(2):268-74.

55. Garisch JA, Wilson MS. Prevalence, correlates, and prospective predictors of non-suicidal self-injury among New Zealand adolescents: crosssectional and longitudinal survey data. Child Adolesc Psychiatry Ment Health. 2015;9(1):28

56. Kiekens G, Hasking P, Boyes M, Claes L, Mortier P, Auerbach RP, et al. The associations between non-suicidal self-injury and first onset suicidal thoughts and behaviors. J Affect Disord. 2018;239:171-9.

57. Calvete E, Orue I, Aizpuru L, Brotherton H. Prevalence and functions of non-suicidal self-injury in Spanish adolescents. Psicothema. 2015;27(3):223-8.

58. World Health Organization. Global school-based student health survey, Bangladesh 2014 fact sheet. 2014.

59. World Health Organization. Global school-based student health survey, Bangladesh 2016 fact sheet. 2016.

60. Voss C, Hoyer J, Venz J, Pieper L, Beesdo-Baum K. Non-suicidal selfinjury and its co-occurrence with suicidal behavior: a epidemiologicalstudy among adolescents and young adults. Acta Psychiatr Scand. 2020;142(6):496-508.

61. Grandclerc S, De Labrouhe D, Spodenkiewicz M, Lachal J, Moro MR. Relations between nonsuicidal self-injury and suicidal behavior in adolescence: a systematic review. PLoS One. 2016;1 1(4):e0153760.

62. Chapman AL, Gratz KL, Brown MZ. Solving the puzzle of deliberate self-harm: the experiential avoidance model. Behav Res Ther. 2006;44(3):371-94.

63. Fox KR, Franklin JC, Ribeiro JD, Kleiman EM, Bentley KH, Nock MK. Meta-analysis of risk factors for nonsuicidal self-injury. Clin Psychol Rev. 2015;42:156-67.

64. Wichstrøm L. Predictors of non-suicidal self-injury versus attempted suicide: similar or different? Arch Suicide Res. 2009;13:105-22.

65. Klonsky ED, Muehlenkamp JJ. Self-injury: a research review for the practitioner. J Clin Psychol. 2007;63(11):1045-56.

66. Handley T, Rich J, Davies K, Lewin T, Kelly B. The challenges of predicting suicidal thoughts and behaviours in a sample of rural Australians with depression. Int J Environ Res Public Health. 2018;15(5):928.

67. Soto-Sanz V, Piqueras JA, Rodríguez-Marín J, Pérez-Vázquez MT, Rodríguez-Jiménez T, Castellví P, et al. Self-esteem and suicidal behaviour in youth: a meta-analysis of longitudinal studies. Psicothema. 2019;31:246-54

\section{Publisher's Note}

Springer Nature remains neutral with regard to jurisdictional claims in published maps and institutional affiliations.

Ready to submit your research? Choose BMC and benefit from:

- fast, convenient online submission

- thorough peer review by experienced researchers in your field

- rapid publication on acceptance

- support for research data, including large and complex data types

- gold Open Access which fosters wider collaboration and increased citations

- maximum visibility for your research: over $100 \mathrm{M}$ website views per year

At BMC, research is always in progress.

Learn more biomedcentral.com/submissions 